\title{
THERAPEUTIC INDICES OF SOME ANTIFUNGAL ORGANIC COMPOUNDS
}

\author{
EUGENE SEBASTIAN J. NIDIRY* \\ Division of Flower and Medicinal Crops, ICAR-Indian Institute of Horticultural Research, Hesaraghatta Lake P.0., Bengaluru, Karnataka, \\ India. Email: nidiry@yahoo.co.in
}

Received: 18 September 2020, Revised and Accepted: 09 November 2020

ABSTRACT

Objective: The objective of the study was to evaluate the therapeutic indices (TIs) some antifungal organic compounds and to compare their safety.

Methods: TIs of 55 organic compounds were evaluated by dividing their mammalian toxicity values given as median lethal doses ([mg/kg] rat, oral) collected from literature by experimentally determined fungitoxicity values evaluated as median effective concentration (EC ${ }_{50}\left[\mathrm{mg}_{\mathrm{L}} \mathrm{L}\right)$ for the mycelial growth inhibition of Colletotrichum gloeosporioides on potato dextrose agar medium.

Results: Large variations in TIs are observed in different classes of compounds, namely, alcohols, carboxylic acids, phenols, esters, and aldehydes. The relationship between carbon chain length of saturated monohydric alcohols and mammalian toxicity shows that toxicity increases from chain length 1 to 5 , declines from 5 to 6 , increases from 6 to 7 , and steadily declines from 7 to 10 . Thus, the relationship is by and large parabolic. The relationship between carbon chain length and molar antifungal activity is also parabolic. In spite of this, large differences are found in TIs making 1-decanol $(\mathrm{TI}=42.1)$ a very safe antifungal compound and 1-pentanol $(\mathrm{TI}=0.17)$ a hazardous antifungal compound. This is because mammalian toxicity reaches a maximum around carbon chain length of 5, while in the case of antifungal activity, it reaches a maximum around carbon chain length of 10.

Conclusions: Among the 55 compounds, whose TIs were evaluated, some compounds with high TIs (>10) which can be considered safe as antifungal compounds are citronellol, geraniol, 1-decanol, 1-octanol, phenyl acetaldehyde, methyl anthranilate, 1-naphthol and 2-naphthol. Some compounds with low TIs $(<0.50)$ which can be considered hazardous as antifungal compounds are resorcinol, hydroquinone, oxalic acid, and acetyl acetone.

Key words: Therapeutic indices, Safe antifungal compounds, Hazardous antifungal compounds, Median lethal doses, Median effective concentrations.

(C) 2021 The Authors. Published by Innovare Academic Sciences Pvt Ltd. This is an open access article under the CC BY license (http://creativecommons.org/ licenses/by/4.0/) DOI: http://dx.doi.org/10.22159/ajpcr.2021v14i1.39804. Journal homepage: https://innovareacademics.in/journals/index.php/ajpcr

\section{INTRODUCTION}

Fungi are the causal organisms of many diseases of man, animals, and plants. They also cause post-harvest spoilage of agricultural products. Natural and synthetic antifungal compounds have been extensively used to control fungi [1-4].

Development of new antifungal compounds is based on extensive structure-activity relationship (SAR) studies on existing antifungal compounds. In earlier publications from this institute, SARs of several such compounds were reported [5-9]. However, high activity of any compound does not make it a good candidate to be recommended for human use because of the possibility of that compound having high toxicity to human beings also. Thus, therapeutic index (TI) $[10,11]$ also known as selective toxicity coefficient $[12,13]$ which is the ability of a compound to injure one kind of living matter without harming some other kind even though both are in intimate contact is considered as an important criterion for recommending any compound for its safe use as antifungal compound. Since this awareness is important, TI values of 55 common organic compounds whose antifungal activity values had been reported earlier from this institute [5-9] were evaluated and are reported in this paper. These TI values were calculated by taking quotient of mammalian toxicity expressed as median lethal doses $\left(\mathrm{LD}_{50} \mathrm{mg} / \mathrm{kg}\right.$ [rat, oral]) collected from literature to antifungal activity expressed as median effective concentration $\left(\mathrm{EC}_{50}[\mathrm{mg} / \mathrm{L}]\right)$ for the mycelial growth inhibition of Colletotrichum gloeosporioides on potato dextrose agar (PDA) medium. Large variation in TI values is observed in different classes of compounds. The variation in the case of monohydric saturated straight chain alcohols is interpreted in terms of SAR studies.

\section{METHODS}

The percent mycelial growth inhibitions of $C$. gloeosporioides on PDA medium at five different concentrations the compounds were determined by poisoned food technique [14]. The median ECs for mycelial growth inhibition $\left(\mathrm{EC}_{50}\right)$ were calculated by probit analysis [15]. The $\mathrm{LD}_{50}$ values were collected from literature [16,18-27]. Therapeutic indices (TIs) of each compound were evaluated by taking quotient of $\mathrm{LD}_{50}(\mathrm{mg} / \mathrm{kg})$ to $\mathrm{EC}_{50}(\mathrm{mg} / \mathrm{L})$.

\section{RESULTS}

The data on mammalian toxicity, fungitoxicity, and TIs of 55 compounds are presented in Table 1 . The listed compounds consist of 23 alcohols, 8 carboxylic acids, 8 phenols, 6 esters, 4 aldehydes, 4 ketones, 1 indole, and 1 amine. For SAR studies of saturated monohydric straight chain alcohols, which are the first nine compounds listed in Table 1, partition coefficient, molar antifungal activity, and molar mammalian toxicity values were calculated and these are presented in Table 2.

\section{DISCUSSION}

Large variations are seen in the TIs within any class of compounds.

The first nine compounds in Table 1 are saturated monohydric straight chain alcohols. Even within these nine compounds, large variations in terms of $\mathrm{TI}$ are seen making 1 -decanol $(\mathrm{TI}=42.1)$ a very safe antifungal compound and 1-pentanol ( $\mathrm{TI}=0.17)$ hazardous as an antifungal compound. The molar antifungal activity values $\left(\mathrm{pEC}_{50}[\mathrm{moles} / \mathrm{L}]\right)$ and molar mammalian toxicity values $\left(\mathrm{pLD}_{50}[\mathrm{moles} / \mathrm{kg}]\right)$ of these compounds are presented in Table 2. It is obvious that in the case of monohydric straight chain alcohols, hydrophobicity increases with carbon chain length [7]. The mammalian toxicity increases up to carbon chain length of 5 , then it shows a slight decline for carbon chain length of 6 , then it increases for carbon chain length of 7 and then decreases steadily up to chain length of 10 . Thus, the relationship between carbon chain length and mammalian toxicity is by and large parabolic. This is invariably because of the parabolic relationship between 
Table 1: Therapeutic indices of some common antifungal organic compounds

\begin{tabular}{|c|c|c|c|c|c|c|}
\hline S. No. & Compound & Chemical class & $\mathrm{LD}_{50}(\mathrm{mg} / \mathrm{Kg})$ & Reference for $L D_{50}$ & $\mathrm{EC}_{50}(\mathrm{mg} / \mathrm{L})$ & TI \\
\hline 1 & Methanol & Alcohol & 5628 & {$[18]$} & 24,687 & 0.23 \\
\hline 2 & Ethanol & Alcohol & 7060 & [20] & 17,683 & 0.40 \\
\hline 3 & 1-Propanol & Alcohol & 1870 & [18] & 8679 & 0.22 \\
\hline 4 & 1-Butanol & Alcohol & 790 & [20] & 3694 & 0.21 \\
\hline 5 & 1-Pentanol & Alcohol & 370 & [20] & 2129 & 0.17 \\
\hline 6 & 1-Hexanol & Alcohol & 720 & [21] & 1271 & 0.57 \\
\hline 7 & 1-Hepanol & Alcohol & 500 & [20] & 546 & 0.91 \\
\hline 9 & 1-Decanol & Alcohol & 4720 & [20] & 112 & 42.14 \\
\hline 10 & Citronellol & Alcohol & 3450 & [20] & 84 & 41.07 \\
\hline 11 & Geraniol & Alcohol & 3600 & [22] & 100 & 36.00 \\
\hline 12 & Benzyl alcohol & Alcohol & 1250 & [18] & 1181 & 1.06 \\
\hline 13 & Phenyl ethyl alcohol & Alcohol & 1609 & [23] & 1000 & 1.61 \\
\hline 14 & 2-Propanol & Alcohol & 5045 & [20] & 18,175 & 0.28 \\
\hline 15 & 2-Methyl 1-propanol & Alcohol & 2460 & [22] & 8205 & 0.30 \\
\hline 16 & 3-Methyl 1-butanol & Alcohol & 1300 & [20] & 3713 & 0.35 \\
\hline 18 & Menthol & Alcohol & 2046 & [19] & 452 & 4.53 \\
\hline 19 & Neomenthol & Alcohol & 3180 & [21] & 488 & 6.52 \\
\hline 20 & Tertiary butyl alcohol & Alcohol & 3500 & [20] & 17106 & 0.20 \\
\hline 21 & Linalool & Alcohol & 2790 & [20] & 1090 & 2.56 \\
\hline 22 & Ethylene glycol & Alcohol & 4700 & [20] & 34,050 & 0.14 \\
\hline 23 & Glycerol & Alcohol & 4090 & [20] & 59,665 & 0.07 \\
\hline 24 & Acetic acid & Carboxylic acid & 3310 & [20] & 838 & 3.95 \\
\hline 25 & Propionic acid & Carboxylic acid & 2600 & {$[20]$} & 343 & 7.58 \\
\hline 26 & Lactic acid & Carboxylic acid & 3543 & [22] & 4767 & 0.74 \\
\hline 27 & Benzoic acid & Carboxylic acid & 1700 & [20] & 843 & 2.02 \\
\hline 28 & 4-Hydroxybenzoic acid & Carboxylic acid & 6000 & [19] & 2485 & 2.41 \\
\hline 29 & Oxalic acid & Carboxylic acid & 375 & [25] & 1153 & 0.33 \\
\hline 30 & Tartaric acid & Carboxylic acid & 7500 & [20] & 5230 & 1.43 \\
\hline 31 & Citric acid & Carboxylic acid & 3000 & [22] & 6703 & 0.45 \\
\hline 32 & Phenol & Phenol & 317 & [20] & 233 & 1.36 \\
\hline 33 & Catechol & Phenol & 300 & [25] & 239 & 1.26 \\
\hline 34 & Resorcinol & Phenol & 301 & [20] & 1540 & 0.20 \\
\hline 37 & Phloroglucinol & Phenol & 4000 & [25] & 9959 & 0.40 \\
\hline 38 & 1-Naphthol & Phenol & 1870 & [20] & 60 & 31.17 \\
\hline 39 & 2-Naphthol & Phenol & 1960 & [20] & 46 & 42.61 \\
\hline 40 & Ethyl acetate & Ester & 11300 & [16] & 8414 & 1.34 \\
\hline 41 & Ethyl acetoacetate & Ester & 3980 & [20] & 2423 & 1.64 \\
\hline 42 & Menthyl acetate & Ester & 5001 & [27] & 1263 & 3.96 \\
\hline 43 & Benzyl acetate & Ester & 2490 & [22] & 999 & 2.49 \\
\hline 44 & Methyl anthranilate & Ester & 2910 & [21] & 149 & 19.53 \\
\hline 45 & Benzyl benzoate & Ester & 1700 & [26] & 19,480 & 0.09 \\
\hline 46 & 1-Hexanal & Aldehyde & 4890 & [21] & 2363 & 2.07 \\
\hline 47 & Phenyl acetaldehyde & Aldehyde & 1550 & [20] & 278 & 5.58 \\
\hline 48 & Benzaldehyde & Aldehyde & 1300 & [20] & 927 & 1.40 \\
\hline 49 & $p$-Anisaldehyde & Aldehyde & 1510 & [20] & 712 & 2.12 \\
\hline 50 & Acetone & Ketone & 5800 & [20] & 118,584 & 0.05 \\
\hline 51 & Methyl isobutyl ketone & Ketone & 2080 & [24] & 12,609 & 0.16 \\
\hline 52 & Acetyl acetone & Ketone & 55 & [20] & 1587 & 0.03 \\
\hline 53 & Menthone & Ketone & 1600 & [23] & 1761 & 0.91 \\
\hline 54 & Indole & Indole & 1000 & [22] & 187 & 5.35 \\
\hline 55 & Aniline & Amine & 250 & [22] & 457 & 0.55 \\
\hline
\end{tabular}

$\mathrm{LD}_{50}:$ Median lethal dose $\left(\mathrm{mg} / \mathrm{Kg}\right.$, rat, oral) collected from the respective references in the next column, $\mathrm{EC}_{50}$ : Median effective concentration (mg/L) for the mycelial growth inhibition of Colletotrichum gloeosporioides on PDA medium, TI: Therapeutic index

hydrophobicity (partition coefficient) and mammalian toxicity. The relationship between carbon chain length (hydrophobicity) and antifungal activity is also parabolic. However, in this case, the activity increases up to carbon chain length of 10 . Earlier studies $[7,17]$ have shown that antifungal activity of straight chain alcohols decreases after chain length of 10. This explains the low therapeutic index (hazardous nature) of 1-pentanol and high therapeutic index (safety) of compounds such as 1-octanol and 1-decanol. These high TIs of unsaturated alcohols such as citronellol and geraniol may also be because they are C-10 alcohols. Alcohols with low TIs include methanol, ethanol, propanol and butanol, 1-pentanol, and 1-octen-3-ol.
In the case of carboxylic acids also, large variation is seen in TIs making propionic acid a very safe antifungal compound and oxalic acid hazardous as an antifungal compound. In the case of phenols, 1-naphthol and 2-naphthol can be considered safe antifungal compounds while resorcinol and hydroquinone can be considered hazardous as antifungal compounds. Among esters, benzyl benzoate has low therapeutic index. Methyl anthranilate has very high therapeutic index and can be considered safe. Among aldehydes, phenyl acetaldehyde with high therapeutic index can be considered as a safe antifungal compound. Since all the ketones given in Table 1 have low TI values, they cannot be considered as safe antifungal compounds. Indole with high TI can be considered safe 
Table 2: Calculated partition coefficients, molar fungitoxicity, and molar mammalian toxicity values of monohydric straight chain alcohols

\begin{tabular}{|c|c|c|c|c|c|}
\hline S. No. & Compound & No. of carbons & CLogP & $\mathrm{pEC}_{50}($ moles $/ \mathrm{L})$ & $\mathrm{pLD}_{50}(\mathrm{moles} / \mathrm{Kg})$ \\
\hline 1 & Methanol & 1 & -0.77 & 0.11 & 0.75 \\
\hline 2 & Ethanol & 2 & -0.11 & 0.42 & 0.81 \\
\hline 3 & 1-Propanol & 3 & 0.43 & 0.83 & 1.51 \\
\hline 4 & 1-Butanol & 4 & 0.97 & 1.30 & 1.97 \\
\hline 5 & 1-Pentanol & 5 & 1.51 & 1.62 & 2.38 \\
\hline 6 & 1-Hexanol & 6 & 2.05 & 1.92 & 2.15 \\
\hline 7 & 1-Hepanol & 7 & 2.59 & 2.33 & 2.37 \\
\hline 9 & 1-Decanol & 10 & 4.21 & 3.15 & 1.52 \\
\hline
\end{tabular}

CLogP: Calculated partition coefficient [7]. $\mathrm{pEC}_{50}(\mathrm{moles} / \mathrm{L})$ : Negative logarithm of median effective molar concentration for mycelial growth inhibition of Colletotrichum gloeosporioides on PDA medium $\mathrm{pLD}_{50}$ (moles/kg): Negative logarithm of median molar $\mathrm{LD}_{50}$ (rat, oral)

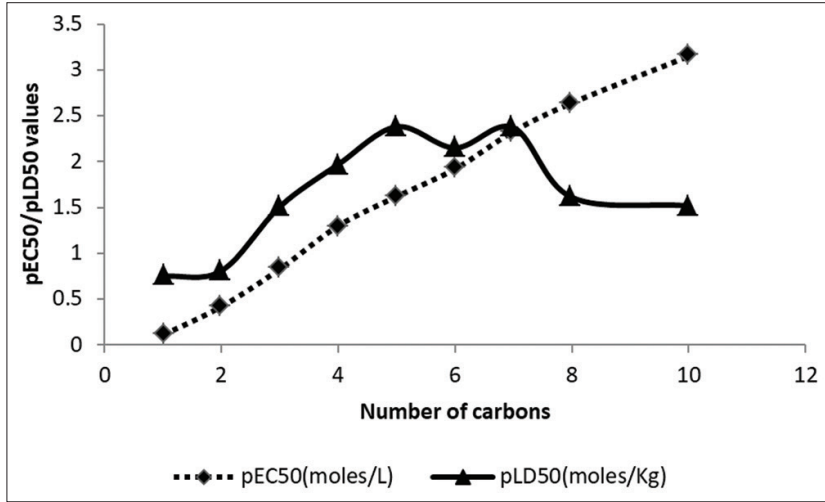

Fig. 1: Variation in fungitoxicity $\left[\mathrm{pEC}_{50}(\mathrm{moles} / \mathrm{L})\right]$ and mammalian toxicity $\left[\mathrm{pLD}_{50}(\mathrm{moles} / \mathrm{Kg})\right]$ of monohydric saturated straight chain alcohols

as an antifungal compound, but aniline with low TI is unsafe as an antifungal compound.

\section{CONCLUSIONS}

Among the 55 antifungal organic compounds whose therapeutic indices (TI) were evaluated, some compounds with high therapeutic indices ( $\mathrm{TI}>10$ ) which can be considered safe as antifungal compounds are citronellol, geraniol, 1-decanol, 1-octanol, phenyl acetadehyde, methyl anthranilate, 1-naphthol and 2-naphthol. Some compounds with low therapeutic indices $(\mathrm{Tl}<0.50)$, which can be considered hazardous as antifungal compounds are resorcinol, hydroquinone, oxalic acid and acetyl acetone.

\section{ACKNOWLEDGMENT/FUNDING}

The research work was fully funded by ICAR-Indian Institute of Horticultural Research and author gratefully acknowledges the encouragement given by Director of the Institute.

\section{AUTHORS' CONTRIBUTIONS}

Eugene Sebastian J. Nidiry was involved in the evaluation of fungitoxicity data $\left(\mathrm{EC}_{50}\right)$, collection of mammalian toxicity data $\left(\mathrm{LD}_{50}\right)$ from literature, and calculation of TIs and interpretation of the data.

\section{CONFLICTS OF INTEREST}

The author declares that there are no conflicts of interest.

\section{REFERENCES}

1. Raj T, Kumar P, Rathee R, Dubey KK. Screening of some medicinal plants for their antimicrobial activities. Int J Pharm Pharm Sci 2016;8:202-6.

2. Khan FAK, Sangshetti JN. Design, synthesis and molecular docking study of hybrid quinolone-4-yl-oxadiazoles/oxathiadiazoles as potent antifungal agents. Int J Pharm Pharm Sci 2015;7:223-9.

3. Kumar A, Kumar S, Sharma V. A review article: Antifungal activity of eucalyptus genus. Int J Pharmacol Clin Sci 2019;3:122-32.

4. Soni A, Dahiya P. Screening of phytochemicals and antimicrobial potential of extracts of Vetiver zizanoides and Phragmites karka against clinical isolates. Int J App Pharm 2017;9:83-90.

5. Nidiry ESJ. Structure-fungitoxicity relationships of the monoterpenoids of the essential oils of peppermint (Mentha piperita) and scented geranium (Pelargonium graveolens). J Essent Oil Res 1998;10:628-31.

6. Nidiry ESJ. Structure-fungitoxicity relationships of some volatile flavour constituents of the edible mushrooms Agaricus bisporus and Pleurotus florida. Flavour Frag J 2001;16:245-8.

7. Nidiry ESJ. Quantitative structure-fungitoxicity relationships of some monohydric alcohols. J Agric Food Chem 2003;51:5337-43.

8. Nidiry ESJ. Structure-antifungal activity relationships of some organic compounds with varying number of hydroxyl groups for their inhibition of Colletotrichum gloeosporioides. Internet Electron J Mol Des 2005;4:803-12.

9. Nidiry ESJ, Babu CS. Antifungal activity of tuberose absolute and some of its constituents. Phytother Res 2005;19:447-9.

10. Muller PY, Milton MN. The determination and interpretation of therapeutic index in drug development. Nat Rev Drug Discov 2012;11:751-61.

11. Trevor A, Katzung B, Masters S, Knuidering-Hall M. Pharmacodynamics. In: Pharmacology Examination and Board Review. $10^{\text {th }}$ ed., Ch. 2. New York: McGraw-Hill Medical; 2013. p. 17.

12. Aniszewski T. Alkaloids-secrets of Life. Amsterdam, Netherlands: Elsevier; 2007. p. 208.

13. Albert A. The basis of selective toxicity. Ann NY Acad Sci 1965;123:5-18.

14. Nene YL, Thapliyal PN. Fungicides in Plant Disease Control. New Delhi: Oxford and IBH Publishing Co. Pvt. Ltd.; 2002. p. 531.

15. Finney DJ. Probit Analysis. Cambridge: Cambridge University Press; 1981. p. 283-7.

16. Available from: www.tedpella.com

17. Hansch C, Lien EJ. Structure-activity relationships of some antifungal agents, a survey. J Med Chem 1971;14:653-70.

18. Available from: http://www.en.wikipedia.org.

19. Available from: www.tera.org.

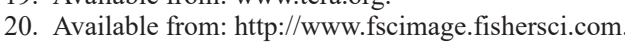

21. Available from: htttp://www.pubchem.ncbi.nlm.nih.gov.

22. Available from: http://www.fishersci.com.

23. Available from: http://www.goodscentscompany.com.

24. Available from: www.paintdocs.com.

25. Available from: http://www.merckmillipore.com.

26. Available from: http://www.datasheets.scbt.com.

27. Available from: www.oxfordlabchem.com. 